The committee's members were selected by Secretary of Health Louis W. Sullivan in July 1991 from experts in infectious diseases, nosocomial infections, epidemiology, public health, and related fields. The committee is charged with providing advice and guidance to the director, $\mathrm{CDC}$, and the director, NCID, regarding strategies for surveillance, prevention, and control of nosocomial infections in US hospitals.

The two-day meeting included an overview of HIP activities and recent accomplishments, ongoing nosocomial infection problems of concern to HIP and historical perspectives of $\mathrm{CDC}$ guidelines for the prevention and control of nosocomial infections. Three CDC guidelines were scheduled for revision, including the guideline for prevention and control of nosocomial pnuemonia, the guideline for isolation precautions in hospitals, and the guideline for prevention of intravascular infections. The committee will meet again in December 1992.

The committee is composed of 11 public members and one federal member. Members serve for four-year overlapping terms. Dr. Walter H. Hierholzer, Jr., Yale-New Haven Hospital, is committee chair, and Julia S. Garner, HIP is executive secretary. Other committee members are Drs. Donald E. Craven, Boston City Hospital; David W. Fleming, Oregon Department of Human Resources; Susan W. Forlenza, Nassau County Medical School, New York; Donald A. Goldmann, Children's Hospital, Boston; Robert W. Haley, University of Texas Southwestern Medical Center at Dallas; John W. Maupin, Jr., Morehouse School of Medicine; C. Glen Mayhall, University of Tennessee, Mem- phis; Rita D. McCormick, University of Wisconsin Hospital and Clinics; Ronald L. Nichols, Tulane University School of Medicine; Christine C. Sanders, Creighton University School of
Medicine; and Edward S. Wong, McGuire Veterans Affairs Hospitals, Richmond, Virginia. Management and support services will be provided by the HIP, NCID.

\title{
National Conference on Prevention of Device-Mediated Bloodborne Infections
}

The Centers for Disease Control, the Food and Drug Administration, and the Occupational Safety and Health Administration are sponsoring "Frontline Healthcare Worker: A National Conference on Device-Mediated Bloodbome Infections." This three-day conference will focus on sharps injuries and performance safety of medical devices and instruments; bring together device manufacturers and users/purchasers to facilitate understanding of needs and interventions pertaining to device-mediated infections; and facilitate private-sector initiatives for technology advancement, including the development of infection prevention devices and strategies.

The conference will be held August 17-19, 1992, in Washington DC. Information regarding conference fees and accommodations will be available from PACE Enterprises, Inc., Attn: Laura Timperio, 17 Executive Park Dr., Suite 200, Atlanta, GA 30329. Telephone (404) 633-8610; FAX (404) 633-8745.

\section{SHEA News and Newsletter Editor Search}

The five-tear term of the current editor of the Journal's SHEA News and of the SHEA quarterly Newsletter expires in December 1992. The Publications Committee is anxious to receive names of individuals who wish to be considered as candidates for this position. SHEA members who are interested and those who would like to submit names of candidates should contact Dr. William Scheckler, Chair, Publications Committee, Department of Family Medicine and Practice, University of Wisconsin, 777 South Mills St., Madison, WI 53715. Telephone (608) 263-3637; FAX (608) 263-5813.

B rief items of interest for the SHEA News or New sletter may be sent to Robert A. Weinstein, MD, SHEA, Newsletter Editor, Division of Infectious Diseases, Michael Reese Hospital, Lake Shore D rive at 31st St., Chicago, IL 60616; FM (312) 791-3577. Copy must be typed, doublespaced, and may not exceed five pages. 


\section{ABBOTT Lifeshield" MAKING THE CONNECTION WITH SAFETY}

